\title{
Supercritical Fluid Adsorption of Domperidone on Silica Aerogel
}

\author{
Giuseppe Caputo \\ Dipartimento di IngegneriaIndustriale, Universitàdeglistudi di Salerno, Fisciano, Italy \\ Email: gcaputo@unisa.it
}

Received March 17, 2013; revised April 17, 2013; accepted May 10, 2013

Copyright (C) 2013 Giuseppe Caputo. This is an open access article distributed under the Creative Commons Attribution License, which permits unrestricted use, distribution, and reproduction in any medium, provided the original work is properly cited.

\begin{abstract}
Silica aerogel (SA) was loaded with domperidone to demonstrate the potentiality of adsorption processes based on the usage of supercritical carbon dioxide to treat poorly water-soluble drugs, forming new kinds of drug delivery systems. The effects of pressure, temperature and solution concentration on loaded SA were studied. Adsorption isotherms were measured at $35^{\circ} \mathrm{C}$ and $45^{\circ} \mathrm{C}$ and fitted with Langmuir model. Release kinetics of the adsorbed drug were also evaluated by in vitro dissolution tests. Results showed that domperidone can be uniformly dispersed into the aerogel and that the release rate of domperidone from the composite, constituted by drug and silica aerogel, is much faster than that of the crystalline drug. The proposed adsorption method is suitable for the production of domperidone fast release tablets.
\end{abstract}

Keywords: Silica Aerogel; Adsorption; Domperidone; Drug Delivery Systems; Adsorption Mechanisms

\section{Introduction}

The poor water solubility of some drugs limited their bioavailability. A fast dissolving system can be defined as a dosage form for oral administration, which when placed in mouth, rapidly dispersed or dissolved increasing compliance and efficacy of the therapy. Fast dissolving and fast dispersing drug delivery system may offer a solution to these problems [1]. Domperidone (DMP), a dopamine antagonist, is widely used in the treatment of nausea and vomiting in the dose range of $10-40 \mathrm{mg} /$ day. It has a low water solubility at low $\mathrm{pH}$ that limits its bioavailability in the gastric fluid. When given as an immediate release tablet, its onset of action is after half an hour and the drug effect lasts for $4-7 \mathrm{~h}$ [2]. DMP has an even more reduced solubility in alkaline $\mathrm{pH}$. Because oral dosage forms are exposed to an environment of increasing $\mathrm{pH}$, the poorly soluble DMP molecules may get precipitated in the intestinal fluid resulting in low DMP bioavailability $(<15 \%)$ which therefore, may not minimize the rate of vomiting [1,2]. A possible approach for ensuring maximum bioavailability in the intestinal fluid is the increase of DMP solubility after adsorption at molecular level on a proper host matrix.

To improve the dissolution rate of drugs, different techniques have been developed [3]. The most common approach is based on particle size reduction that can be achieved by processes based on micronization or nano- suspension. Each technique utilizes different equipment for the reduction of the particle size [4,5]. In the field of supercritical fluids, various promising techniques of micronization of drugs and excipients with $\mathrm{SC}-\mathrm{CO}_{2}$ have been developed [6-8] and also the use of the less expensive $\mathrm{SC}-\mathrm{N}_{2}$ is being explored [9]. An alternative way to improve the availability of a drug is its dispersion on a biocompatible substrate [10]. Silica based materials used as substrate are widely employed as additives, free flow agents and drug carriers also in commercial products. A special class of silica materials is silica aerogels (SA). They are low density nano-porous solids with a fine openpore structure that exhibit unique properties, such as high porosity $(90 \%-99 \%)$, high surface area (400 - 1000 $\left.\mathrm{m}^{2} / \mathrm{g}\right)$, extremely low density $\left(0.003-0.15 \mathrm{~g} / \mathrm{cm}^{3}\right)$. These properties allow them to be used as a host matrix for drug delivery. Silica aerogels were recently shown to be a potential candidate for oral drug delivery systems [11-13]. A promising method to adsorb a drug into porous substrates is supercritical (SC) deposition or adsorption [11, 12,14-16]. Essentially, the process involves the dissolution of the active molecules in a supercritical fluid and the impregnation of the substrate by its exposure to this solution. Supercritical carbon dioxide $\left(\mathrm{SC}-\mathrm{CO}_{2}\right)$ is commonly used due to its relatively good solvent power for various drugs, mild critical temperature $\left(31^{\circ} \mathrm{C}\right)$, low critical pressure (7.4 MPa) and inertness. After the remo- 
val of the SCF by expansion, a drug-loaded matrix free of solvent residues is obtained. This method takes advantage of the unique properties of SCFs. Indeed, a SCF possesses a unique combination of gas-like and liquidlike properties, which can be adjusted by small changes in temperature or pressure.

Low viscosity and high diffusivity of $\mathrm{SC}-\mathrm{CO}_{2}$ allows a rapid equilibration and micropore penetration of the fluid phase within the matrix. SCFs also have zero surface tension that not only facilitates the rapid permeation and diffusion into porous substrates, but also avoids the pore collapse of SA that occurs using organic liquids, due to capillary stresses caused by the liquid-vapor menisci within pores.

In this work, the adsorption of domperidone on SA was studied at various conditions of temperature and concentration. The experimental work basically consisted in 1) study of the solubility of DMP in $\mathrm{SC}-\mathrm{CO}_{2}$ to know the saturation conditions as a function of temperature and pressure; 2) study of adsorption isotherms to know the relationship between concentration of DMP in the fluid phase and in the solid phase at equilibrium; 3) in vitro drug release tests to study the properties of the composite material and its potentiality for industrial applications.

\section{Experimental}

\subsection{Materials}

Hydrophilic silica aerogel (SA) in form of monolithic blocks was purchased from Merketech Int. (USA). The nominal density is $0.1 \mathrm{~g} / \mathrm{cm}^{3}$ and the surface area is 800 $\mathrm{m}^{2} / \mathrm{g}$ and the mean pore size is about $20 \mathrm{~nm}$. Deposition experiments were performed using cubic blocks of $1 \mathrm{~cm}$ obtained by cutting SA monoliths with a knife. $\mathrm{CO}_{2}$ research grade 4.8 was purchased from SON (Italy). All products were used as received. Domperidone (purity 98\%) was kindly donated by Italchimicis. p.a. (Pomezia, Italy).

\subsection{Solubility Measurements}

The solubility of nimesulide in $\mathrm{SC}-\mathrm{CO}_{2}$ was determined experimentally at $45^{\circ} \mathrm{C}$ in the pressure range $10.0-18.0$ MPa using a static synthetic method [17]. A variable volume view cell was used for measurements (Figure 1). The cell is equipped with anair-driven piston (A) that allows to smoothly change the internal volume from 32 to $61 \mathrm{~cm}^{3}$. One front and one back sapphire windows allow to look inside the cell. An optical microscope (Nikon SMZ800, 6× mag.) allows to inspectsolubilization of small crystals. The cell is heated by electric cartridges (Watlow, USA) whose thermal control is guaranteed by a PID controller (Watlow, USA). The temperature inside the cylinder is measured by a J-type thermocouple with an accuracy of $\pm 0.1^{\circ} \mathrm{C}$. Pressure is measured by a digital gauge manometer (Parker, USA). A specific amount of domperidone was weighed with an analytical balance (Shimadzu, Japan) having repeatability $<0.1 \mathrm{mg}$ and put at the bottom of the cell. The cell was closed and heated to the set-up temperature. Then, $\mathrm{CO}_{2}$ preheated to the same temperature was pumped in the cell up to the final pressure by means of a manual piston pump (P1). The system was stored for 15 min under mechanical stirring to ensure that DMP were dissolved.

Starting from this condition, the cell volume was gently changed until cloud point was observed.

Cloud point indicates the formation of solid phase from the solution. The pressure at which cloud point was observed is assumed as solubility point.

\subsection{Adsorption Experiments}

Adsorption isotherms were obtained using a static method described elsewhere [15]. The main part of the plant is an autoclave, consisting of a stainless steel cylinder having an internal volume of $100 \mathrm{~mL}$. The autoclave was loaded with accurately weighed amounts of SA (about $0.25 \mathrm{~g}$ ) cubic monoliths wrapped in filter paper in order to pre-

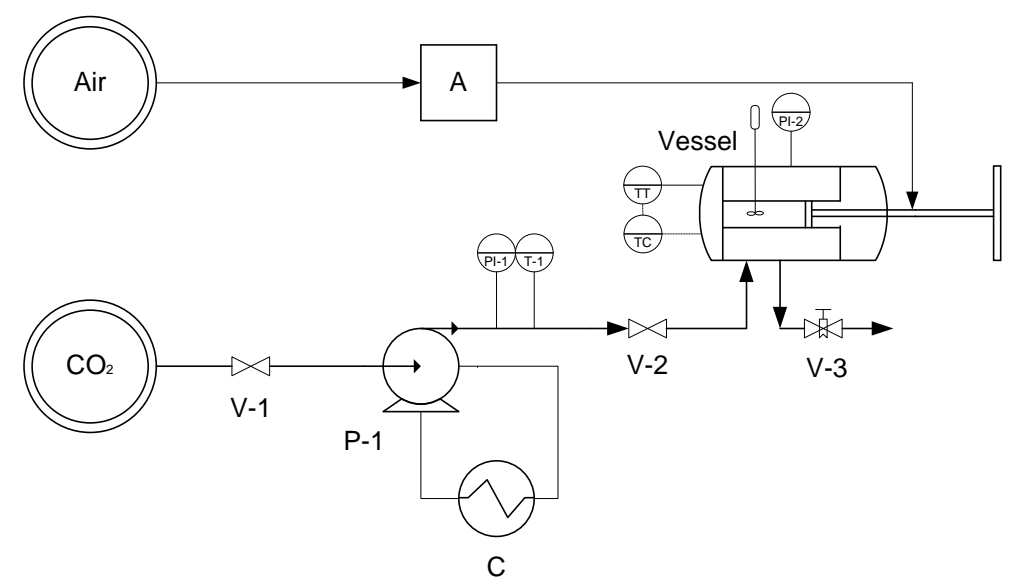

Figure 1. Experimental set-up for the measurement of the solubility of drugs in SC-CO . 
vent their contact with the solid domperidone placed on the bottom of the autoclave. A weighed amount of the drug was placed in a small container opened on the top to allow contact with $\mathrm{CO}_{2}$ and mounted axially on the impeller shaft. The autoclave was closed, heated to the fixed temperature and, then, $\mathrm{CO}_{2}$ was slowly added to the system at constant flow rate of $10 \mathrm{~mL} / \mathrm{min}$. The amount of $\mathrm{CO}_{2}$ in the autoclave was calculated from the density data. When the working pressure was reached, the system was stored for a fixed time. Then, $\mathrm{CO}_{2}$ was vented out at a constant pressure drop of about $0.1 \mathrm{MPa} / \mathrm{min}$. After the vessel was cooled, the impregnated SA was removed and weighed. The amount of adsorbed compound was determined by the weight change of the SA using an analytical balance. The thermodynamics of adsorption was quantified by an adsorption isotherm, which relates to the concentration of the adsorbate in the SC$\mathrm{CO}_{2}$ phase to the concentration of the adsorbate in the solid phase. Adsorption isotherms were obtained at $35^{\circ} \mathrm{C} /$ 23.0 MPa and $45^{\circ} \mathrm{C} / 23.0 \mathrm{MPa}$. Adsorption experiments were repeated three times. The difference was less than $5 \%$ between experiments probably due to loss of material by entrainment during depressurization through the filter paper, and to the deposition of non-adsorbed material on the surface of SA.

\subsection{Drug Dissolution Rate Analysis}

Domperidone dissolution profiles were obtained with a USP apparatus 2, consisting of Varian 7025, paddle dissolution tester (Varian, Agilent Technologies Italia s.p.a, Italy). All studies were run according to the USP 25 paddle method: $150 \mathrm{rpm}, 900 \mathrm{~mL}$ of dissolution medium, T $=37.2^{\circ} \mathrm{C} \pm 0.1^{\circ} \mathrm{C}$, sink conditions. The adsorbed SA monoliths were coarsely crushed in a mortar and suspended in water. Then, the aqueous solution was continuously pumped to a flow cell in a spectrophotometer and absorbance was recorded at $284 \mathrm{~nm}$.

Dissolution curves were studied with samples of SA equivalent to $10 \mathrm{mg}$ of DMP in $900 \mathrm{~mL}$ of buffer solution. Following the method of Nagarsenker et al. [2], two buffer solutions were used. A buffer solution at $\mathrm{pH}=1.2$ and a buffer solution at $\mathrm{pH}=6.8$. The first solution represents the gastric fluid, the second solution represents the intestinal fluid.

\section{Results and Discussion}

The experimental work basically consisted in 1) study of the solubility of DMP in SC-CO $\mathrm{CO}_{2}$ to know the saturation conditions as a function of temperature and pressure; 2) study of adsorption isotherms to know the relationship between concentration of DMP in the fluid phase and in the solid phase at equilibrium; 3) in vitro drug release study.

\subsection{Solubility Measurements}

The knowledge of DMP solubility is necessary to prepare saturated liquid phase solution for adsorption experiments. In literature, no solubility data of DMP in $\mathrm{SC}-\mathrm{CO}_{2}$ were found.

The solubility of DMP in $\mathrm{SC}-\mathrm{CO}_{2}$ was measured at $45^{\circ} \mathrm{C}$ under different pressures. Experimental results are shown in Figure 2. In the pressure range 11.0 - 23.0 MPa, the DMP solubility varied from $15 \times 10^{-6}$ to $110.3 \times 10^{-6}$ mole fraction (y). As expected, the solubility increased with pressure as a result of the increase in the density of $\mathrm{CO}_{2}$. A solubility of DMP in SC-CO $\mathrm{CO}_{2}$ of $121 \times 10^{-6}$ mole fraction was also measured at $35^{\circ} \mathrm{C} / 23.0 \mathrm{MPa}$.

\subsection{Isotherms of Adsorption}

The adsorption isotherms of DMP on SA were obtained at $35^{\circ} \mathrm{C}$ and $45^{\circ} \mathrm{C}$ and $23.0 \mathrm{MPa}$. These conditions have been selected because they correspond to the maximum solubility of DMP in SC- $\mathrm{CO}_{2}$ measured in this study. To ensure that equilibrium was reached, the adsorption process was carried out for a period of $24 \mathrm{~h}$. The corresponding isotherm curves are presented in Figure 3 where the DMP loading is reported as qe (mmol of DMP /grams of silica aerogel) and the solution concentration is expressed as $\mathrm{C}_{0}\left(\mathrm{mmol}\right.$ of $\mathrm{DMP} /$ liter of $\left.\mathrm{CO}_{2}\right)$.

Obviously, the concentration of DMP on SA increases with increasing concentration of DMP in $\mathrm{CO}_{2}$; the maximum loading obtained is $0.035 \mathrm{mmol}_{\mathrm{DMP}} / \mathrm{g}_{\mathrm{SA}}$ that corresponds to $1.5 \mathrm{wt} \%$ of DMP with respect to SA. Thus, in $1 \mathrm{~g}$ of SA can be adsorbed $15 \mathrm{mg}$ of DMP. Because the conventional therapeutic dose of DMP is $10 \mathrm{mg}$, it should be possible to prepare a $0.66 \mathrm{~g} \mathrm{SA}$ tablet containing the therapeutic dose of DMP.

Brunauer et al. [18] classified the isotherms that are

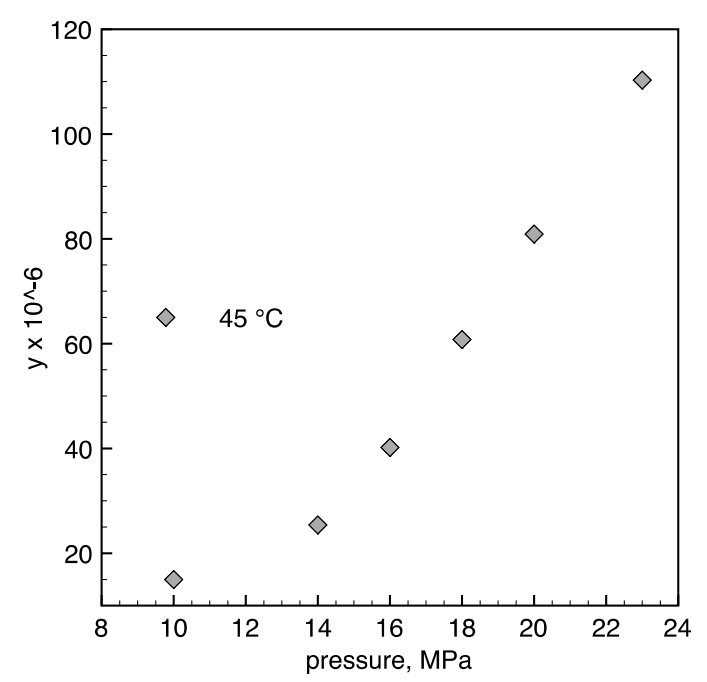

Figure 2. Solubility of DMP in $\mathrm{SC}-\mathrm{CO}_{2}$ as a function of pressure. Solubility is expressed as molar fraction $(y)$. 


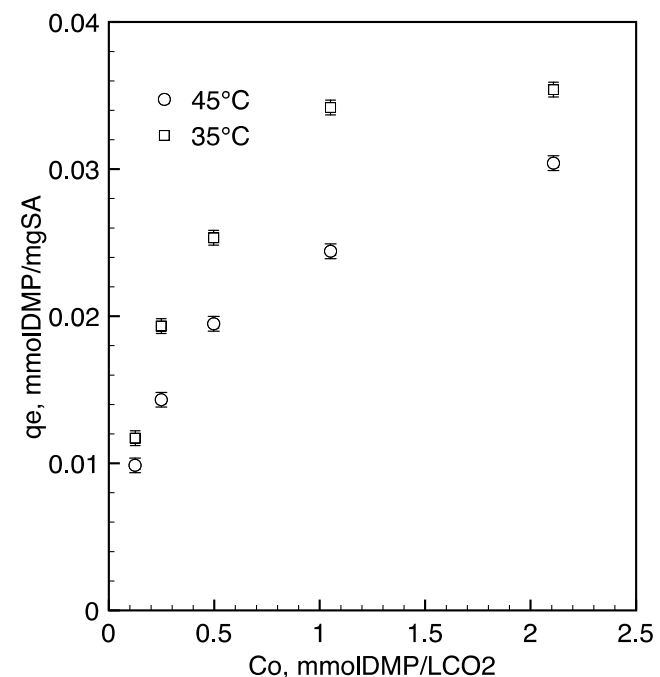

Figure 3. Adsorption isotherm for domperidone on silica aerogel at $35^{\circ} \mathrm{C} / 23.0 \mathrm{MPa}$ and $45^{\circ} \mathrm{C} / 23.0 \mathrm{MPa}$.

convex upward throughout (type I) as "favorable" to uptake of solute, whereas the ones that are concave upward throughout (type III) as "unfavorable" to uptake of solute. According to this classification, the isotherms obtained at $35^{\circ} \mathrm{C}$ and $45^{\circ} \mathrm{C}$ are favorable.

The Langmuir adsorption isotherm is most widely used for the sorption of organic compound from liquid and gaseous solutions. The model is based on several basic assumptions: a) sorption takes place on specifichomogeneous sites within the adsorbent; b) a molecule occupies a site; c) the adsorbent has a finite capacity for the adsorbate (at equilibrium, a saturation point is reached and further adsorption can proceed); d) all sites are identical and energetically equivalent (adsorbents are structurally homogeneous). The linear form of the Langmuir equation is represented as follows:

$$
\frac{C e}{q e}=\frac{1}{q_{\max } \times K_{L}}+\frac{C_{e}}{q_{\max }}
$$

where $q_{\max }$ is the maximum capacity of adsorbate to form a complete monolayer on the surface (mmolDMP/gSA), $\mathrm{K}_{\mathrm{L}}$ is the Langmuir constant related to the heat of adsorption. By plotting Ce/qe versus $C_{e}$, it is possible to obtain the value of $q_{\max }$ and $K_{L}$ from the slope and the intercept. The Langmuir isotherm model for DMP on SA are found to be linear over the whole concentration range studied with correlation coefficient $R^{2}=0.989$. These high correlation coefficient values strongly support the fact that the adsorption closely follows the Langmuir model of adsorption in both examined cases. The parameters found were $q_{\max }=0.032 \mathrm{mmol}_{\mathrm{DMP}} / \mathrm{g}_{\mathrm{SA}}$ and $K_{L}=69.44$ for the isotherm at $45^{\circ} \mathrm{C} ; q_{\max }=0.036 \mathrm{mmol}_{\mathrm{DMP}} / \mathrm{g}_{\mathrm{SA}}$ and $K_{L}=$ 194.79 for the isotherm at $35^{\circ} \mathrm{C}$.

Large $K_{L}$ constant indicates a good affinity of adsorbents for the adsorbate resulting in a stable adsorption product. Thus, there is much stronger binding of DMP to $\mathrm{SA}$ at $35^{\circ} \mathrm{C}$.

\subsection{Dissolution Test}

We studied the dissolution rate of the drug in vitro. Water solution at $\mathrm{pH}=1.2$ and $\mathrm{pH} 6.8$ were chosen as dissolution media following the recommendation US Pharmacopeia. The dissolution profiles of the drug from the powdered loaded aerogel were compared with that of commercial DMP tablets. Release kinetics are shown in Figure 4. In the buffer at $\mathrm{pH}=1.2$ the dissolution of DMP from loaded aerogel is faster than dissolution of DMP-tablets. $65 \%$ of DMP dissolves from the aerogel within 15 minutes, whereas dissolving $65 \%$ of the crystalline drug takes $30 \mathrm{~min} .90 \%$ of DMP dissolves after $2 \mathrm{~h}$
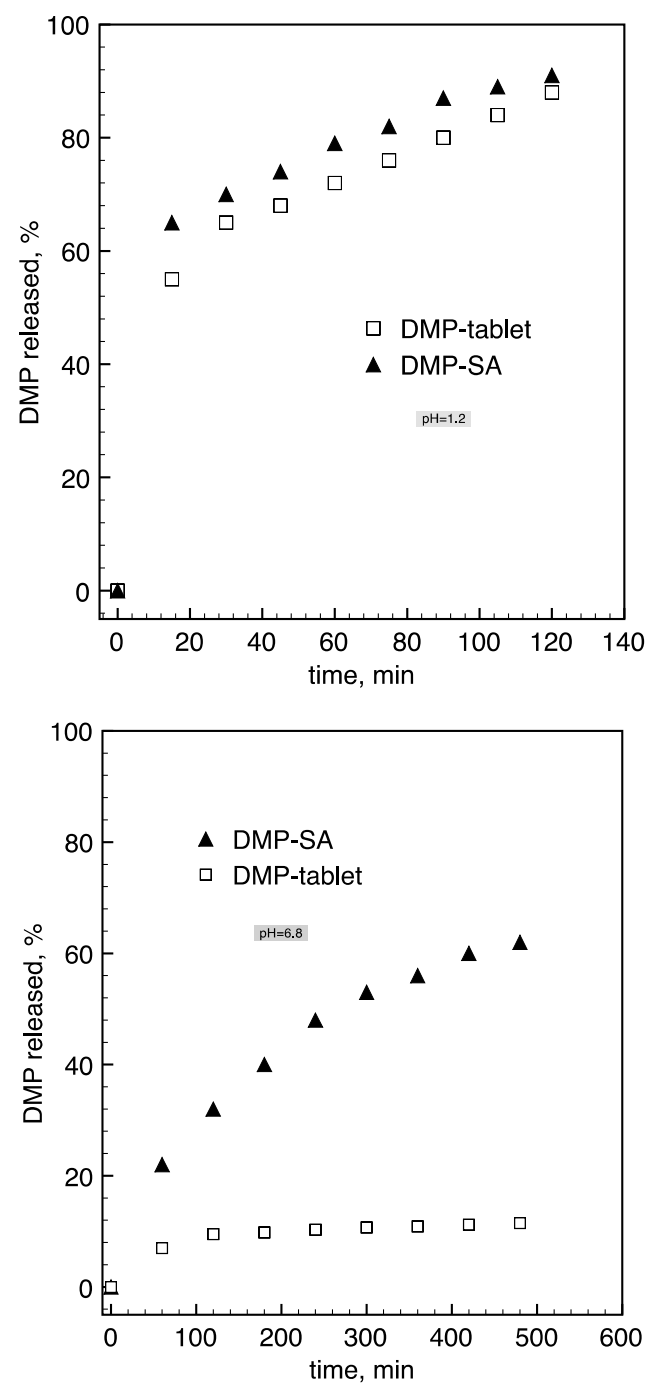

Figure 4. Release kinetics of DMP-tablets (commercial DMP) and DMP adsorbed on silica aerogel in buffer solution at $\mathrm{pH}=1.2$ (left) and $\mathrm{pH}=6.8$ (right). Dissolution curves were obtained from samples equivalent to $10 \mathrm{mg}$ of DMP in $900 \mathrm{~mL}$ of buffer solution. 
in both cases.

In the buffer at $\mathrm{pH}=6.8$ representing the intestinal fluid, a lower solubility of DMP was expected. Indeed, $7 \%$ of DMP dissolves from tabletwithin one hour and than the concentration increases up to $11.5 \%$ within 8 hours. DMP-SA has a much faster dissolution rate. $22 \%$ of DMP dissolves within one hour and $62 \%$ dissolves within 8 hours. These results are in good agreement with data reported by Nagarsenker et al. [2].

Thus, the use of hydrophilic aerogels as a carrier promotes fast release of the drug both at $\mathrm{pH} 1.2$ and 6.8 with a marked gain in the latter case. This effect can be explained by both an increase of specific surface area of the drug adsorbed on the aerogel and its non-crystalline structure in this state. In the case of the crystalline drug, even with a very small particle size, the crystal should be destroyed before the drug can be actually dissolved. If the drug is adsorbed on the aerogel, this step is eliminated and the dissolution process is accelerated. Another important effect is the partial collapse of aerogel structure in water. Hydrophilic aerogels are rapidly wetted with water, so the drug molecules are surrounded with water allowing a fast dissolution of drugs [12].

\section{Conclusion}

In this study, it was demonstrated that the supercritical fluid adsorption is an effective way to incorporate domperidone into a microporous silica aerogel. This technique allows to obtain ultra pure drug delivery systems avoiding the use of organic solvents. Particularly, supercritical adsorption is suitable to generate domperidone/ SA composites for the fast release of domperidone. It is possible to prepare a $0.66 \mathrm{~g} \mathrm{SA}$ tablet containing $10 \mathrm{mg}$ therapeutic dose of domperidone with an enhanced drug release rate both in the gastric and intestinal fluid. The enhanced dissolution rate can be explained by both the increase in the specific surface area of the adsorbed drug and its non-crystalline structure in the formulation. The adsorption isotherms can be fitted to a Langmuir isotherm model confirming the monolayer adsorption of DMP on SA, with the maximum monolayer adsorption capacities of $0.036 \mathrm{mmol}_{\mathrm{DMP}} / \mathrm{g}_{\mathrm{SA}}$ at $35^{\circ} \mathrm{C}$ and 0.032 $\mathrm{mmol}_{\mathrm{DMP}} / \mathrm{g}_{\mathrm{SA}}$ at $45^{\circ} \mathrm{C}$. These results encourage the development of industrial application of the proposed process.

\section{Acknowledgements}

Italchimicis.p.a. (Pomezia, Italy) is kindly acknowledged for financial support.

\section{REFERENCES}

[1] R. B. Parmar, A. H. Baria, H. M. Tank and S. D. Faldu,
"Formulation and Evaluation of Domperidone Fast Dissolving Tablets," International Journal of PharmTech Research, Vol. 1, No. 3, 2009, pp. 483-487.

[2] M. S. Nagarsenker, S. D. Garad and G. Ramprakash, "Design, Optimization and Evaluation of Domperidone Coevaporates," Journal of Controlled Release, Vol. 63, No. 1-2, 2000, pp. 31-39. doi:10.1016/S0168-3659(99)00177-7

[3] S. Pinnamaneni, N. G. Das and S. K. Das, "Formulation Approaches for Orally Administered Poorly Soluble Drugs," Pharmazie, Vol. 57, No. 5, 2002, pp. 291-300.

[4] J. C. Chaumeil, "Micronization: A Method of Improving the Bioavailability of Poorly Soluble Drugs," Methods \& Findings in Experimental \& Clinical Pharmacology, Vol. 20, 1998, pp. 211-215.

[5] V. B. Patravale, A. A. Date and R. M. Kulkarni, "Nanosuspensions: A Promising Drug Delivery Strategy," Journal of Pharmacy and Pharmacology, Vol. 56, No. 7, 2004, pp. 827-840. doi:10.1211/0022357023691

[6] P. York, U. B. Kompella and B. Y. Shekunov, "Supercritical Fluid Technlogy for Drug Development," Marcel Dekker, New York, 2004. doi:10.1201/9780203021378

[7] E. Reverchon, G. Caputo, S. Correra and P. Cesti, "Synthesis of Titanium Hydroxide Nanoparticles in Supercritical Carbon Dioxide on the Pilot Scale," The Journal of Supercritical Fluids, Vol. 26, No. 3, 2003, pp. 253-261. doi:10.1016/S0896-8446(02)00163-8

[8] S. Liparoti, R. Adami, G. Caputo and E. Reverchon, "Supercritical Assisted Atomization: PVP as Carrier for Drug with Poor Solubility in Water," Journal of Chemistry, 2013, Article ID: 801069. doi:10.1155/2013/801069

[9] G. Caputo, S. Liparoti, R. Adami and E. Reverchon, "Use of Supercritical $\mathrm{CO}_{2}$ and $\mathrm{N}_{2}$ as Dissolved Gases for the Atomization of Ethanol and Water," I\&ECR, Vol. 51, No. 36, 2012, pp. 11803-11808.

[10] A. M. Hillery, A. W. Lloyd and J. Swarbrick, "Drug Delivery und Targeting," Taylor \& Francis, London, New York, 2001.

[11] I. Smirnova, S. Suttiruengwong and W. Arlt, "Feasibility Study of Hydrophilic and Hydrophobic Silica Aerogels as Drug Delivery Systems," Journal of Non-Crystalline Solids, Vol. 350, 2004, pp. 54-60.

[12] I. Smirnova, S. Suttiruengwong, M. Seiler and W. Arlt, "Dissolution Rate Enhancement by Adsorption of Poorly Soluble Drugs on Hydrophylic Silica Aerogels," Pharmaceutical Development and Technology, Informa Healthcare, Vol. 9, 2005, pp. 443-452.

[13] U. Guenther, I. Smirnova and R. H. H. Neubert, "Hydrophilic Silica Aerogel as Dermal Drug Delivery SystemsDithranol as a Model Drug," European Journal of Pharmaceutics and Biopharmaceutics, Vol. 69, 2008, pp. 935 942.

[14] I. Smirnova, J. Mamic and W. Arlt, "Adsorption of Drugs on Silica Aerogels," Langmuir, Vol. 19, 2003, pp. 85218525.

[15] G. Caputo, M. Scognamiglio and I. De Marco, "Nimesulide Adsorbed on Silica Aerogel Using Spercritical Carbon Dioxide," Chemical Engineering Research and De- 
sign, Vol. 90, No. 8, 2012, pp. 1082-1089. doi:10.1016/j.cherd.2011.11.011

[16] G. Caputo, I. De Marco and E. Reverchon, "Silica Aerogel-Metal Composites Produced by Supercritical Adsorption," The Journal of Supercritical Fluids, Vol. 54, No. 2, 2010, pp. 243-249.

doi:10.1016/j.supflu.2010.05.003
[17] G. Brunner, "Gas Extraction, Topics in Physical Chemistry," Vol. 4, Steinkopff, Springer, New York, Darmstadt 1994, pp. 123-125.

[18] S. Brunauer, L. S. Deming, W. E. Deming and E. Teller, "On a Theory of the van der Waals Adsorption of Gases," Journal of the American Chemical Society, Vol. 62, 1940, pp. 1723-1732. 